\title{
Largest Dimension of Residual Neoplasm
}

National Cancer Institute

\section{Source}

National Cancer Institute. Largest Dimension of Residual Neoplasm. NCI Thesaurus.

Code C137853.

The largest single dimension of the residual tumor after surgical resection. 